\section{ИСКУССТВЕННЫЙ ИНТЕЛЛЕКТ ВО ФРАНЦУЗСКОМ ПРАВЕ}

\begin{abstract}
Аннотация. Во Франции использование искусственного интеллекта стремительно развивается во многих областях, в том числе и в сфрере правосудия. Такие коренные изменения порождают проблемы, связанные с вопросами ответственности и распределением прав интеллектуальной собственности в связи с применением технологий искусственного интеллекта.

Ключевые слова: искусственный интеллект, прогностическое правосудие, полномочие принятия решений, ответственность, интеллектуальная собственность, автоматизированная обработка персональных данных.
\end{abstract}

DOI: 10.17803/2311-5998.2021.77.1.047-055

\section{A. DUFLOT,}

Lecturer at the Jean Moulin Lyon III University, (Lyon, France), Lawyer

directorate.internationalcouncil@msal.ru 69008, France, Lyon, Cours Albert Thomas, 6

\title{
ARTIFICIAL INTELLIGENCE IN FRENCH LAW
}

\begin{abstract}
The use of artificial intelligence in France is growing and intensifying in many areas, particularly in the field of justice. This revolution create problems with the liability and intellectual property of systems using artificial intelligence.

Keywords: Al, predictive justice, decision-making power, liability, intellectual property, automated processing of personal data.
\end{abstract}

скусственный интеллект (ИИ) является темой номер один во Франции, и пандемия COVID-19 заметно ускорила развитие дискуссии об использовании технологий ИИ в различных сферах общественной жизни, таких как здравоохранение, образование, оборона и общественная безопасность, экономика и правосудие ${ }^{1}$.

Искусственный интеллект играет центральную роль и в так называемом «Зеленом соглашении для Европы», и в восстановлении экономики после пандемии COVID-19².

1 Haenlein M., Kaplan A. A brief history of Artificial Intelligence: On the Past, Present, and Future of Artificial Intelligence. California Management Review. 2019.

2 Tamma P., Schaart E., Gurzu A. Europe's Green Deal plan unveiled // Politico. 11 décembre 2019 ; Benakis Th. Parliament supports European Green Deal // European Interest. 15 janvier 2020.

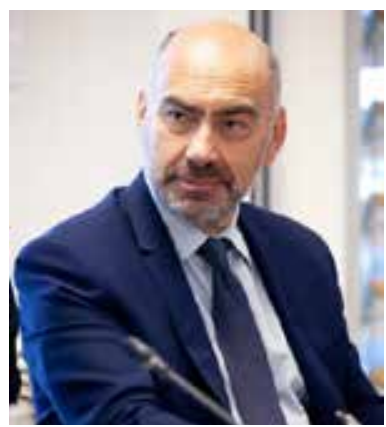

Ален Дюфло, преподаватель Университета Лион III имени Жана Мулена (Лион, Франция), юрист directorate. internationalcouncil@ msal.ru 69008, Франция, г. Лион, Cours Albert Thomas, 6 
Президент Франции Эммануэль Макрон объявил одним из приоритетов деятельности своего правительства развитие потенциала применения ИИ и превращение Франции в мирового лидера в области искусственного интеллекта. Для достижения этой цели он пообещал выделить 1,5 млрд евро (примерно 1,7 млрд долларов США) для технологий фринансирования ИИ к 2022 г., «чтобы предотвратить утечку мозгов и догнать доминирующих сегодня на глобальном рынке американских и китайских технологических гигантов». Параллельно французское правительство предприняло ряд мер по предотвращению проблем, связанных с правовым регулированием искусственного интеллекта ${ }^{3}$.

Кроме того, французское правительство экспериментирует с использованием технологий ИИ в сфере управления. В частности, в 2017 г. апелляционные суды Ренна и Дуэ протестировали программное обеспечение так называемого прогностического правосудия в отношении ряда дел, рассмотренным судами второй инстанции ${ }^{4}$.

Однако Франция еще не приняла всеобъемлющее законодательство об ИИ и алгоритмах 5 , поскольку, как и другие европейские государства, она ожидает принятия новых рамочных документов на уровне ЕС, посвященных регулированию ИИ, о чем было объявлено в начале 2021 г. Не сто́ит забывать, что развитие ИИ является одним из трех основных приоритетов для $\mathrm{EC}$, который хочет стать эталоном и мировой державой в этой стратегической сфрере.

Новое французское законодательство, чтобы сохранить свою гибкость и масштабность в целях адаптации к стремительно внедряющимся технологическим инновациям в области ИИ, должно иметь очень прочную этическую основу. Защита индивидуальных свобод и уважение к человеческой личности должны стать приоритетом и непререкаемым требованием.

По этой причине Французский парламент обсуждает Этическую хартию об ИИ, которая могла бы быть включена в преамбулу французской Конституции и, таким образом, иметь ценность гораздо бо́льшую, чем национальное законодательство, и сравняться по значимости с Всеобщей декларацией прав человека.

В декабре 2017 г. Национальная комиссия по информатике и гражданским свободам (National Commission on Computer Technology and Civil Liberties, CNIL) подготовила доклад на тему «Этические аспекты машинных алгоритмов и искусственного интеллекта» ${ }^{6}$.

В докладе CNIL предлагаются два общих принципа и шесть конкретных рекомендаций. Речь идет о принципах лояльности (loyaute, что также можно перевести как «благонадежность») и предупредительности. Первый принцип отражает идею о том, что машинные алгоритмы не должны нарушать интересы своих

3 Villani C. Donner un sens à l'intelligence artificielle. Rapport au Premier ministre. 2018.

4 Coustet $T$. L'utilisation de l'outil Predictice déçoit la cour d'appel de Rennes // Dalloz actualité, 16 oct. 2017 ; Prevost S., Sirinelli P. Madame Irma, Magistrat. D. 2017. P. 557, n. 11; Benesty M. L'open data et l'open source, des soutiens nécessaires à une justice prédictive fiable ? // JOAL. 2017.

5 Droit de l'intelligence artificielle / Bensamoun A. (dir.), Loiseau G. (dir.) // LGDJ. 2019.

6 Comment permettre à l'Homme de garder la main, Rapport sur les enjeux éthiques des algorithmes et de l'intelligence artificielle // CNIL. 15 déc. 2017. P. 16. 
пользователей - не только как потребителей, но и в более широком смысле как граждан и членов сообществ или других групп, интересы которых могут быть затронуты использованием технологий ИИ.

Второй принцип относится к идее о том, что постоянное развитие и непредсказуемость технологий ИИ требует регулярного методического обсуждения всеми заинтересованными сторонами. CNIL даны следующие шесть рекомендаций:

- изучение норм этики всеми, кто участвует в разработке и использовании ИИ;

- проведение работы по обеспечению понятности машинных алгоритмов для пользователей;

- разработка алгоритмов обеспечения прав и свобод человека и противодействующих так называемому эфффекту «черного ящика»;

- создание национальной системы по аудиту машинных алгоритмов;

- поощрение исследований в области этики ИИ и запуск масштабного национального исследовательского проекта, ориентированного на обеспечение общих интересов;

- создание корпоративных структур по контролю за соблюдением этических норм.

Принцип приоритета человека и его интересов над ИИ должен быть отражен, в частности, в области распределения прав интеллектуальной собственности в отношении систем ИИ и результатов их деятельности.

Правовое регулирование ИИ во Франции уже сейчас затрагивает область правосудия (I), а в дальнейшем должно быть отражено в конструкции ответственности (II) и распределения прав интеллектуальной собственности (III).

\section{І. Французское правосудие и ИИ}

Недавно во Франции был принят план цифровой трансформации, целью которого является создание к 2022 г. полностью функциональной цифровой службы государственного правосудия, позволяющей (среди прочего) пользователям следить за движением дела в режиме онлайн. Но именно человек (гражданин) находится в центре этого проекта. Трансформация является дополнительным средством доступа к правосудию. Она не заменяет традиционные способы передачи дел в суды ${ }^{7}$.

Цифровая доступность судебных решений также будет способствовать активному внедрению технологий искусственного интеллекта. Проект предоставляет широкие возможности как для обычных граждан, так и для специалистов в области права (в том числе судей), которые будут иметь упрощенный доступ к прецедентному праву, поскольку искусственный интеллект выступает в качестве инструмента поддержки принятия решений․

7 Goodman J. Robots in Law: How Artificial Intelligence is Transforming Legal Services. 1st ed. Ark Group. 2016. ISBN 978-1-78358-264-8.

8 Garapon A. La justice digitale. Paris : Presses universitaires de France, 2018. 
Данные цели должны быть достигнуты при обеспечении уважения частной жизни, гарантированной ст. 8 Европейской конвенции о защите прав человека и основных свобод 1950 г. В решениях, которые публикуются в сети Интернет, любой контент, который может позволить идентифицировать соответствующих лиц, должен быть удален. Многие другие принципы, которые должны будут направлять развитие систем искусственного интеллекта, определенные Европейской комиссией по эффективности правосудия (ЕКЭП) в ее Этической хартии, включают уважение основных прав человека, недискриминацию, нейтралитет, прозрачность, контроль пользователей, безопасность хостинга и контролируемое использование прогностического правосудия 9 .

Необходимо проведение широкомасштабного общественного обсуждения в целях критической оценки роли технологий ИИ в системе правосудия. Расширение доступа к правосудию путем снижения стоимости судебных разбирательств за счет использования систем искусственного интеллекта может показаться благоприятным результатом, но только если при этом не снижается качество отправления правосудия. Именно поэтому инструменты ИИ должны быть должным образом адаптированы к среде правосудия с учетом принципов и процедур, лежащих в основе проведения судебного разбирательства ${ }^{10}$.

Таким образом, суды должны сконцентрироваться на рассмотрении следующих вопросов:

- возможность для всех участвующих сторон идентифицировать использование систем ИИ при рассмотрении дела. Возможность идентифицировать использование ИИ: стороны, вовлеченные в судебный процесс, всегда должны иметь возможность идентифицировать в рамках судебного решения выводы, являющиеся результатом использования систем ИИ. Кроме того, должно быть четкое разделение между данными или результатами работы системы искусственного интеллекта и другими данными в рамках рассмотрения дела;

- отсутствие делегирования судье полномочий по принятию решений. Роль инструментов ИИ должна быть определена таким образом, чтобы использование этих инструментов не создавало препятствий для принятия судьей решения. Ни при каких обстоятельствах судья не должен делегировать все или часть своих полномочий по принятию решений системе ИИ. Инструменты ИИ не должны ни ограничивать, ни регулировать полномочия судьи по принятию решений, например в контексте принятия автоматизированного решения. Когда решение судьи (частично) основано на выводах, вытекающих из использования инструментов искусственного интеллекта, они должно быть должным образом обоснованы в тексте решения;

- возможность проверки ввода данных и аргументации системы ИИ. В тех случаях, когда решение, скорее всего, будет основываться, полностью или частично, на данных или результатах, предоставленных инструментом ИИ, сторонам и (или) их адвокатам должна быть предоставлена возможность получить

9 Ferrié $S$. Intelligence artificielle : Les algorithmes à l'épreuve du droit au procès équitable // JCP G. 2018. 502. n. 11.

${ }^{10}$ Brian Ch. The Alignment Problem: Machine Learning and Human Values. W. W. Norton. 2020ISBN 978-0-393-63582-9. 
доступ к этому инструменту и оценить его характеристики, используемые данные и релевантность результатов, которые он предоставляет. В результате так называемое "обучающее программное обеспечение" должно использоваться только в той мере, в какой возможна проверка того, как система ИИ достигла предлагаемого результата, и отличий выводов, сформулированных системой ИИ, от личной позиции судьи;

- возможность обсуждения и оспаривания выводов, сформулированных системой ИИ. Стороны судебного процесса должны иметь возможность обсуждать данные и выводы, полученные из автоматизированной системы. Именно поэтому применение систем ИИ всегда должно осуществляться вне стадии устного рассмотрения дела и с учетом разумного времени для обсуждения сторонами.

В результате вмешательства, целью которого стало ограничение фрормирующегося сектора судебной аналитики и прогнозирования, французское правительство запретило публикацию статистической информации о решениях судей, установив пятилетний срок тюремного заключения в качестве максимального наказания для любого, кто нарушит данное положение (ст. 226-18, 226-24 и 226-31 Уголовного кодекса Франции).

Новый Закон от 23 марта 2019 г. - Закон о реформе правосудия направлен на то, чтобы никто (особенно технологические компании, специализирующиеся на прогнозировании судебных процессов и аналитике) не мог раскрывать общественности модель поведения судей в отношении судебных решений.

Ключевая норма нового закона гласит: «Идентификационные данные мировых судей (магистратов) и представителей судебной власти не могут быть использованы повторно с целью или намерением оценки, анализа, сравнения или прогнозирования их существующей или потенциальной профессиональной практики».

Такой запрет сформулирован в законодательстве впервые. Закон вводит запрет на использование идентификационных данных судей для моделирования поведенческих ситуаций, демонстрирующих то, как некоторые судьи ведут себя по отношению к определенным видам правовых вопросов или аргументам, или как их поведение можно сопоставить с поведением других судей.

Так, проведенное исследование наглядно продемонстрировало, что приговоры, вынесенные утром, были более благоприятными для обвиняемых. С помощью систем ИИ можно узнать, какой тип доказательств или аргументов является наиболее убедительным для того или иного судьи. Применение такого функционала систем ИИ во Франции теперь законодательно запрещено.

Применение систем ИИ в правосудии было легализовано Декретом от 27 марта 2020 г. об автоматизированной обработке персональных данных, который получил наименование Data just decree. Целью принятия данного акта стало реагирование на многочисленные претензии лиц, пострадавших от пандемии COVID-19, которые, возможно, захотят привлечь к ответственности медицинские службы или администраторов за некорректное урегулирование последствий пандемии. Декрет предназначен для того, чтобы предоставить судам и административным органам прозрачную шкалу компенсаций и перечень документации для вынесения судебных решений, а также для оценки на основе 
анализа деятельности системы ИИ влияния законодательства на определение сумм такой компенсации ${ }^{11}$.

Еще одним аспектом правового регулирования использования ИИ является юридическая ответственность.

\section{II. Ответственность и ИИ}

Европейский парламент полагает, что «необходимость полного пересмотра... режимов ответственности отсутствует», вместе с тем она сохраняется только в отношении принятия «конкретных и скоординированных мер».

ЕС формулирует конструкцию ответственности по принципу наделения ею оператора системы ИИ (как фронтенд-оператора, так и бэкенд-оператора). Для «высокорисковых автономных систем искусственного интеллекта», по мнению европейских чиновников, «разумно установить общий режим строгой ответственности» (no-fault responsibility). Все высокорисковые ИИ-системы должны быть исчерпывающе перечислены в предлагаемом к принятию Регламенте ЕС.

Конструкция ответственности будет охватывать «нарушение основополагающих охраняемых законом прав человека» на жизнь, здоровье, фризическую неприкосновенность и собственность.

Конструкция ответственности также должна учитывать размер компенсаций и срок исковой давности.

В дальнейшем следует пересмотреть средства правовой защиты, действующие в рамках систем строгой ответственности (например, системы ответственности за продукцию), особенно с учетом применения средств, связанных с рисками развития систем ИИ².

Также изменения должны коснуться и режимов ответственности как на наднациональном, так и национальном уровнях, с учетом следующих проблем.

1. Свойство самообучения и автономного принятия решений в системах ИИ препятствует использованию традиционного правового обоснования, построенного на концепции «предсказуемости» в качестве основы для привлечения к ответственности. В этом контексте система ИИ может нанести ущерб как в результате традиционного «дефекта», например в программном обеспечении, так и в результате своих «собственных» действий, определяемых данными и алгоритмами, без учета «виновной» составляющей.

Ответственность за причинение ущерба не может быть с легкостью отнесена к «виновной» категории или привязана к наличию дефекта в продукте программного обеспечения (в части наличия конкретной неисправности). В этих условиях можно утверждать, что ответственность за действия, совершаемые системой ИИ, не обязательно должна быть связана с понятием вины (в его традиционном смысле) или «дефекта» (в его традиционном смысле). Примечательно, что

11 Prevost J.-B. Justice prédictive et dommage corporel : perspectives critiques // Gaz. Pal. 30 janv. 2018. n. 312b3. P. 43.

12 Ortega P., Maini V. Deep Mind Safety Team (27 September 2018). Building safe artificial intelligence: specification, robustness, and assurance. Medium. 
действующая Директива ЕС об ответственности за продукцию, хотя и основана на существовании «дефекта», определяет его не в традиционном смысле, а в отношении результата, т.е. «продукт является дефектным, когда он не обеспечивает безопасности, на которую лицо имеет право рассчитывать, принимая во внимание все обстоятельства...» (ст. 6(1)).

2. Возникает вопрос о том, на каких субъектов может распространяться ответственность. Это довольно сложная задача, учитывая непрозрачность функционирования систем ИИ и множественность лиц и юрисдикций. В случае отдельных субъектов также может существовать неопределенность в отношении использования их работы в системе ИИ. Существует ряд способов выявления субъектов ответственности.

Отдельные специалисты предлагают конструкцию строгой ответственности оператора и производителя; или обязанности оператора и производителя проявлять «должную заботу» (duty of care) в случае ответственности за неисправность. В связи с этим следует приветствовать введение понятия оператора как «лица, которое контролирует возникновение рисков, связанных с функционированием ИИ, и которое извлекает выгоду из его функционирования», при этом делается различие между фронтенд- и бэкенд-оператором. Такие операторы, как и производители, должны будут выполнять конкретные обязанности по поддержанию систем в исправном состоянии, что влечет наступление ответственности в случае невыполнения ими таких обязанностей.

Ответственность за ущерб или нарушение индивидуальных прав, возникшие в результате использования системы искусственного интеллекта, должно нести фризическое или юридическое лицо.

3. Вопросы, касающиеся бремени доказывания (charge de la preuve), также нуждаются в пересмотре в контексте систем искусственного интеллекта. Потерпевшие должны иметь право на облегчение бремени доказывания в ситуациях, когда сложности доказывания наличия элемента ответственности являются непропорциональными, выходящими за рамки разумных ожиданий. В некоторых случаях реверсирование бремени доказывания может быть целесообразным, например при отсутствии протоколированной информации о технологии операции или непредоставлении потерпевшему разумного доступа к этой информации.

В тех случаях, когда несколько лиц участвовали в создании системы ИИ и потерпевший не может доказать, кто из этих лиц создал элемент, приводящий к возникновению ущерба, правовые нормы также должны способствовать привлечению лиц к солидарной ответственности перед потерпевшей стороной. В данном контексте должна быть обеспечена возможность подавать иски о возмещении ущерба.

4. Что касается ущерба, то представляется необходимым рассматривать не только физический и материальный ущерб, но и уничтожение данных потерпевшего как ущерб, подлежащий возмещению при определенных условиях. Предъявлять иск о возмещении ущерба могут как потребители, так и представители профессионального сообщества. 
Искусственный интеллект также может представлять угрозу для развития институтов демократии, например, в случае распространения фейковых новостей во время избирательной кампании ${ }^{13}$.

Интегрированность избирательных процессов, избирательных кампаний и избирательных участков была ослаблена во Франции, как и в других странах, что привело к возбуждению уголовных дел. Необходимо сохранять предельную бдительность в отношении манипулирования общественным мнением путем распространения фральшивых новостей, часто с помощью автоматизированных средств. Речь не идет о своеобразных нападках на свободу выражения мнений, скорее, имеется в виду свобода сохранения мнений.

22 декабря 2018 г. во Франции был принят Закон о противодействии манипулированию информацией. Онлайн-платформы теперь несут обязательства по обеспечению прозрачности содержания спонсорской информации и идентичности спонсоров, если фигурируют значительные денежные суммы (порядка 100 евро). Платформы также должны иметь своих юридических представителей на фрранцузской территории. Законодательство учитывает только крупные платформы, т.е. с более чем 5 млн посетителей в месяц. Закон также устанавливает чрезвычайную судебную процедуру, известную как référé anti-infox, направленную на устранение недостатков, связанных с рассредоточением информации, с целью повышения эфффективности выборов.

Заключительным, но не менее значимым аспектом правового регулирования использования систем ИИ является право интеллектуальной собственности.

\section{III. Право интеллектуальной собственности и ИИ}

Принцип приоритета человека над ИИ наиболее наглядно демонстрируется в контексте права интеллектуальной собственности ${ }^{14}$.

Очевидно, что только физическое или юридическое лицо, задействованное в создании алгоритмов, владеет всей полнотой прав интеллектуальной собственности. В то же время, если бы система ИИ не являлась юридическим лицом, она также была бы лишена данной категории прав.

Европейский парламент подчеркивает важность эффективной системы защиты интеллектуальных прав для дальнейшего развития ИИ, включая патентование и защиту авторских прав. Помимо других важных вопросов ключевое значение имеет проблема определения принадлежности прав интеллектуальной собственности на результаты, созданные системами ИИ.

Европейские парламентарии предполагают, что оценка деятельности ИИ сосредоточена на определении воздействия и последствиях применения ИИ в рамках действующей системы, что включает:

- патентное право;

${ }^{13}$ La régulation des fake news et avis factices sur les plateformes, Enguerrand Marique, Alain Strowel // Revue internationale de droit économique. 2019/3. T. XXXIII. P. 383-398.

${ }^{14}$ Larrieu J. Chapitre 9. La propriété intellectuelle et les robots // Journal International de Bioéthique. 2013/4. Vol. 24. P. 125 à 133. 
- защиту товарных знаков;

- авторское право и смежные права, в том числе защиту баз данных и компьютерных программ;

- защиту ноу-хау и коммерческой тайны от несанкционированного приобретения, использования и раскрытия.

Более того, рассматривая развитие ИИ, важно проводить различие между системами и результатами человеческого труда, сделанными при помощи систем ИИ, и результатами деятельности автономных систем ИИ. В связи с этим «результаты деятельности, созданные искусственными агентами или роботами, не подлежат защите авторским правом в целях обеспечения принципа оригинальности», принимая во внимание человеческое участие и творческую составляющую человеческой деятельности.

\section{Заключение}

Франция ожидает принятия новых европейских рамочных правил, посвященных ИИ. При этом совершенно очевидно, что принятие таких правил должно быть незамедлительным, поскольку технологии постоянно меняются и задержка в принятии соответствующей нормативно-правовой базы будет негативным образом сказываться на экономике европейского региона. 